\title{
Uso de Tecnologia Social na constituição do Conselho Gestor de Unidade de Saúde
}

Olga Maria Ramalho de Albuquerque ${ }^{1,2}$, José Henrique Rocha ${ }^{1}$, Karla Silva ${ }^{1}$, Larissa Mesquita $^{1}$, Lucas Azevedo ${ }^{1}$, Patrícia Oliveira ${ }^{1}$, Sara Vieira ${ }^{1}$, Maria Fernanda Melis ${ }^{2}$, Cecile Soriano Rodrigues ${ }^{3}$

olgamaria@unb.br, henriquerochaunb@gmail.com,kk-kassia@hotmail.com, larissaotavianom@hotmail.com, lucascunhaazevedo@hotmail.com, patriciacirqueiraunb@gmail.com, sara.dos.anjos@hotmail.com, mfernanda.melis@gmail.com, cecile_rodrigues@hotmail.com.

${ }^{1}$ Faculdade de Ceilândia - Universidade de Brasília, Brasil

${ }^{2}$ Programa de Pós-Graduação em Propriedade Intelectual e Transferência de Tecnologia para a Inovação Universidade de Brasília, Brasil

${ }^{3}$ Curso de Especialização em Gestão em Saúde UPE/UAB, Brasil

DOI: 10.17013/risti.28.41-56

Resumo: Objetivo: analisar a percepção de graduandos sobre o processo de aprendizagem no Estágio Supervisionado Saúde Coletiva 1 (ESSC 1) da Faculdade de Ceilândia-Universidade de Brasília para constituição do Conselho Gestor de Unidade de Saúde(CGUS) com uso de Tecnologia Social(TS). Metodologia: pesquisaação e análise de conteúdo em um corpus, extraído do relatório e da avaliação, baseada em princípios da metodologia ativa de ensino-aprendizagem e na Teoria do Agir Comunicativo. Resultado: a TS promoveu interação mediatizada pela rede social (WhatsApp) e face-a-face com diferentes atores no exercício da democracia participativa. No ESSC 1 a construção da rede de relacionamento institucional estado/sociedade resultou na eleição do CGUS em atendimento à solicitação da gestora. Conclusão: a dinâmica pedagógica que subsidiou a interlocução entre atores sociais propiciou aos graduandos vivenciarem a participação deles mesmos e destes grupos na implementação na Atenção Primária em Saúde e experimentarem os efeitos da autonomia, emancipação e 'empoderamento'.

Palavras-chave: Promoção da saúde; Participação da comunidade; Tecnologia social; Tecnologia educacional; Formação profissional em saúde.

\section{Use of Social Technology in the constitution of the Health Unit Manager Council}

Abstract: Aim: to analyze undergraduates' perception regarding the learning process in the Supervised Stage of Collective Health 1 (ESSC 1) Faculty of CeilândiaUniversity of Brasília for the constitution of the Health Unit Management Council (CGUS) with Social Technology. Methodology: action research and content analysis in a corpus, extracted from the report and assessment, based on principles of active 
teaching-learning methodology and Theory of Communicative Action. Result: social technology mediatized interaction through social network (WhatsApp) and face-to-face with different actors in the participatory democracy exercise. In the ESSC 1 the construction of the state/society institutional relationship network resulted in the election of the CGUS in response to manager request. Conclusion: the pedagogical dynamics that subsidized the interaction among social actors, allowed undergraduates to experience their own participation and the groups in the implementation of Primary Health Care and to experience the effects of autonomy, emancipation and empowerment.

Keywords: Health promotion; Community participation; Social technology; Educational technology; Health human resource training.

\section{Introdução}

O Estágio Supervisionado em Saúde Coletiva 1 (ESSC 1) é uma disciplina que compõe as trilhas de aprendizagem do sexto semestre do curso de Saúde Coletiva da Faculdade de Ceilândia/Universidade de Brasília (SC-FCE/UnB) e se desenvolve na Atenção Primária à Saúde (APS), na Região de Saúde Oeste: Ceilândia/Brazlândia - Distrito Federal, Brasil (RSOC/B-DF).

Este curso encontra-se em fase de consolidação de sua identidade e de sua atuação no sistema de saúde. A profissão de Sanitarista foi inserida recentemente na Classificação Brasileira de Ocupações, do Ministério do Trabalho brasileiro. As Diretrizes Curriculares Nacionais, aprovadas em junho de 2017, pelo Conselho Nacional de Educação e sua Câmara de Educação Superior, estão em fase de homologação. Para a formação do futuro Sanitarista, o Projeto Político-Pedagógico do Curso (PPC) de SC-FCE/UnB (Universidade de Brasília, 2009, p. 7) estabelece algumas competências dentre as quais o "desenvolvimento de ações de Promoção da Saúde (PS) em diferentes serviços de saúde e outros cenários de atuação"; a "identificação de necessidades junto aos usuários dos serviços e profissionais de saúde"; a "aprendizagem cooperativa em ambientes de trabalho"; a "mobilização e participação em equipes para pesquisa-ação" e a contribuição para ampliar "a participação social” (Universidade de Brasília, 2009, p. 7).

Em muitas ocasiões, a chegada de graduandos de SC-FCE/UnB às Unidades Básicas de Saúde (UBS) para o ESSC 1, levou os gestores a solicitarem tarefas não condizentes com as atribuições dos Sanitaristas, em razão do desconhecimento das prerrogativas próprias desta profissão e da insuficiência de recursos humanos ali existentes. Devido à escassa identificação deles com o seu futuro ofício (Bezerra et al., 2013), antes da entrada na UBS 5 - RSOC/B-DF, os seis graduandos de SC e a professora refletiram sobre sua percepção acerca do ESSC 1, as atribuições do Sanitarista nos processos de trabalho das instituições de saúde, bem como sobre sua inserção no Sistema Único de Saúde (SUS).

A mobilização social (MS) é uma "reunião de sujeitos que definem objetivos e compartilham sentimentos, conhecimentos e responsabilidades para a transformação de uma dada realidade, movidos por um acordo em relação a determinada causa de interesse público" (Braga, Henriques, \& Mafra, 2004, p. 36). Uma das formas utilizadas para a mobilização são as tecnologias sociais (TS) como meio de congregar técnicas e metodologias transformadoras desenvolvidas e/ou aplicadas na interação com a população e resultam em inclusão social. Alguns parâmetros legitimam as TS dentre os 
quais o atendimento a demandas sociais concretas; o subsídio a formas democráticas de tomada de decisão e o fortalecimento da participação ativa da comunidade (ITS, 2004, pp. 130-131).

Estes parâmetros das TS são identificados nas ações para promover saúde que envolve “a 'troca de saberes' e a atuação junto com a comunidade para melhorar qualidade de vida e saúde mediante sua participação no controle desse processo" (Brasil, 2002, com adaptações, p. 2). A participação, elemento convergente que permeia a MS, a TS e a PS, encontra amparo legal nas diretrizes do SUS (Constituição da República Federativa do Brasil, 1988) e em sua regulamentação por meio das Leis 8.080 (1990) e 8.142 (1990), bem como nas Portarias 2.488 (2012) e 2.446 (2014). Adicionalmente o Distrito Federal disponibiliza um conjunto de normas que fundamentam essa participação (Resolução 002, 1995; Lei 4.604, 2011; Resolução 390, 2012).

Sua regulamentação pela Lei 8.142 (1990, p. 1) determina a "participação da comunidade na gestão do SUS em caráter permanente e deliberativo no Conselho de Saúde" como "instância colegiada do SUS em cada esfera de Governo: Ministério da Saúde, Secretaria de Saúde dos Estados, Distrito Federal (DF) e Municípios. Este normativo estabelece a composição, organização, competência e representação paritária fixada em 50\% de usuários, 25\% de trabalhadores e 25\% de prestadores de serviço.

Condizente com o marco legal existente no país, o DF promulgou a Lei 4.604 (2011, p. 1) que "dispõe sobre a organização, composição e atribuições do Conselho de Saúde do DF”. A seguir a Resolução CSDF 002 (1995) estipulou a composição dos Conselhos Gestores das Unidades de Saúde no DF: 60\% de representantes de usuários, 30\% dos trabalhadores e 10\% dos gerentes da unidade de saúde. Entretanto, esse arcabouço normativo em vigor há 20 anos não garantiu a materialização das conquistas legais que representam, pois não havia um único CGUS em funcionamento na RSOC/B-DF.

Consistente com estes conceitos, as tecnologias sócio-educacionais articuladas a aspectos da Teoria do Agir Comunicativo, adotada neste trabalho, se configuram numa abordagem potencialmente capaz de analisar a crise contemporânea da educação, na qual a aprendizagem muitas vezes restringe-se à transmissão de saberes técnicocientífico, apontado pelos críticos como modelo tecnicista (Rocha et al., 2018). O modelo epistemológico da comunicação, desenvolvido por Habermas, fornece aportes para a crítica ao modelo educacional vigente, além de representar um contributo importante para a construção de uma cidadania esclarecida (Habermas, 2012; Menezes, 2014).

Os princípios norteadores da TS foram sumarizados por Otero (ITS, 2004, p. 131) dentre os quais a indissociabilidade entre o "respeito às identidades locais" e a "aprendizagem e participação" num processo contínuo de "compreensão da realidade de maneira sistêmica”. Esse conjunto de iniciativas engatilham diversos elementos de transformação; todo indivíduo é capaz de gerar conhecimento e aprender a partir do momento que está inserido numa cultura e em contato com o mundo, todo indivíduo produz conhecimento e aprende a partir dessa interatuação. Desse modo o emprego da TS favorece a interação com a comunidade e sua inclusão nos processos decisórios (Moresi et al., 2017).

Segundo Gouveia e Gaio (2004; citado por Gouveia, 2004, p. 3) a Sociedade da Informação "recorre predominantemente às tecnologias da informação e comunicação para a troca de informação em formato digital, suportando a interacção entre indivíduos 
e entre estes e instituições, recorrendo a práticas e métodos em construção permanente. Para Gouveia (2004, p. 3) estes autores se referem à "Sociedade da Informação e do Conhecimento como que querendo emendar a excessiva conotação de individualismo e de efêmero que está associado à informação. A informação, enquanto material de apoio à decisão e à acção, está sujeita a um enquadramento - contexto - que lhe dê valor e utilidade. O conhecimento por ser, em grande parte, resultado da partilha coletiva de significados, é necessariamente, construído em sociedade, promovendo valores como a colaboração, a partilha e a interação".

Nesse contexto da sociedade da informação e do conhecimento, Gadotti (2000, pp. 3-9) debate as "perspectivas atuais da teoria e prática da educação” sob o prisma da aquisição de habilidades de "pensar criticamente", "saber trabalhar coletivamente, ter iniciativa, [...] e resolver conflitos". Essa sociedade da informação requer "múltiplas oportunidades de aprendizagem" que se traduzem em "saber comunicar-se; saber pesquisar; [...] saber organizar o próprio trabalho; saber articular o conhecimento com a prática, além de ser independente e autônomo" (Gadotti, 2000, p. 8). É sob esse ângulo de visão que Gadotti (2000) situa a formação de profissionais e as tecnologias pedagógicas empregadas na educação superior.

As perguntas norteadoras deste estudo foram: as estratégias de ensino e aprendizagem adotadas na disciplina ESSC 1 têm se mostrado efetivas na formação de graduandos para desenvolver habilidades e competências, com vistas à mobilização dos sujeitos para a participação? Esse tipo de abordagem reforça nos graduandos a apropriação das suas atribuições como futuros Sanitaristas?

O objetivo dessa pesquisa foi analisar a percepção dos graduandos do curso de SC-FCE/ UnB sobre o processo de ensino aprendizagem no ESSC 1, cujo objetivo era a constituição do Conselho Gestor de Unidade de Saúde (CGUS) por meio do uso de Tecnologias Sociais

\section{Metodologia}

Esse estudo se desenvolveu com base nos pressupostos da pesquisa-ação, tipo de pesquisa social com base empírica em que a concepção e a realização da pesquisa se volta para a resolução de um problema coletivo, "no qual os pesquisadores e os participantes representativos da situação ou do problema estão envolvidos de modo cooperativo ou participativo" (Thiollent, 2008, p. 16).

A disciplina ESSC 1 utiliza a metodologia ativa de ensino-aprendizagem que corresponde a "formas de desenvolver o processo de aprender, utilizando experiências reais ou simuladas, visando às condições de solucionar, com sucesso, desafios advindos das atividades essenciais da prática social, em diferentes contextos” (Berbel, 2011, p. 29). Sua operacionalização ocorreu na UBS 5 - RSOC/B-DF, no segundo semestre de 2016, e enfocou a função política da pesquisa-ação voltada para a formação profissional em saúde e a implementação da "participação e do controle social" (Portaria n. 2.488, 2011, p. 19). O caráter político de intervenção conjunta está em consonância com este dispositivo legal que prevê "o exercício de práticas de cuidado e gestão democráticas e participativas" (Portaria n. 2.488, 2011, p. 19). Isso configura a "validez da norma" na medida em que é "reconhecida como válida por seus destinatários no esforço de entendimento sobre algo no mundo” (Habermas, 2003, p. 35). 
Segundo Thiollent (2008, p. 48) essa vertente política da pesquisa-ação "consiste em estreitar as relações que existem entre a organização e sua base por meio de procedimentos participativos, agregando o maior número possível de seus membros na elucidação dos problemas e das propostas de ação”. O emprego deste método incrementou o exercício da "autonomia como ato político no campo da formação profissional" que é preconizado na metodologia ativa por Berbel (2011, p. 30).

A participação de grupos heterogêneos requerida na pesquisa-ação contou com os graduandos, a professora, a gestora da UBS 5 - RSOC/B-DF, o Conselho Regional de Saúde de Ceilândia (CRSC), o Conselho Distrital de Saúde-DF (CDS-DF), a Diretoria Regional da Atenção Primária em Saúde (DIRAPS) e membros da comunidade representados pelos componentes das instituições que concorreram ao processo eletivo para constituição do CGUS. A importância dessa rede, que se estabeleceu na APS, resultou da consciência de que a mudança e a inovação dependem da existência de um amplo suporte (Keemis \& McTaggart, 2005). Sob esse prisma, o CGUS “tem funções deliberativas, normativas, fiscalizadoras e consultivas. Seus principais objetivos são o acompanhamento, o controle e a avaliação da execução da política de saúde em cada Unidade de Saúde do SUS” (Resolução n. 002, 1995, p. 1).

Tendo a APS como cenário de prática, o eixo primordial de construção do conhecimento no ESSC 1 era o nexo entre a teoria e a prática em um contexto que dá suporte à participação ativa dos graduandos na aprendizagem da qual são sujeitos. Por essa razão, para além de prestar-se ao exercício de interpretação, sua voz compõe o processo da investigação. Isso atende as características da pesquisa-ação: centrar em uma situação concreta; consolidar o relacionamento entre a teoria e a prática; estreitar o vínculo entre pesquisadores e atores, bem como ter alcance sócio político (Dionne, 2007, p. 77). Neste sentido, as categorias "habilidades desenvolvidas na formação profissional", "consensos alcançados para constituição do CGUS e “desafios para a implementação do CGUS” foram utilizadas para analisar a dimensão de ensino-aprendizagem envolvida neste estudo.

Na perspectiva da Teoria do Agir Comunicativo, a concepção de democracia é um aspecto central e não pode haver democracia sem que os cidadãos possam se entender a respeito de proposições aceitas por todos. Para Habermas (2012), o conceito de entendimento, um elemento fundamental de sua teoria, contrapõe-se ao agir instrumental ou racional teleológico. Ou seja, aquele orientado para o êxito, onde o ator escolhe os meios que lhe parecem apropriados e calcula outras consequências da ação desejada. No agir comunicativo, os participantes não se orientam prioritariamente pelo êxito em si mesmo; perseguem seus fins individuais sob a condição de serem capazes de conciliar seus diversos planos de ação com base em definições comuns de situações vividas. Isso implica uma atitude orientada pelo entendimento. Processos de entendimento ou consenso, almejado por via comunicativa tem fundamento racional e não pode ser imposto. Não se pode forçar um consenso por meio de ações vindas de fora ou pela violência. O consenso se consubstancia nas convicções partilhadas (Habermas, 2012, pp. 495-498).

Em Habermas (2012), a questão da esfera pública é uma problemática central. Nesta esfera os atores sociais devem ter condições de decidir sobre as orientações das ações sociais, impulsionados apenas pela disposição de dialogar e atingir um consenso, sem coerções externas ou internas. A categoria "consenso" proposta por Habermas (2012) orientou livremente as análises referentes as ações específicas de constituição do CGUS. 
Ao longo do ESSC 1 os graduandos escreveram um diário de campo como base para o Relatório que entregaram ao final do semestre. E, no último encontro com o grupo, a professora fez uma avaliação final das percepções deles sobre a vivência ali construída. Esse conjunto constituiu o corpus sobre o qual efetuou-se a análise de conteúdo (Bardin, 2011). As principais categorias que vieram em relevo foram as "habilidades desenvolvidas na formação profissional", os "consensos alcançados para constituição do CGUS" e os "desafios para a implementação do CGUS”. O exercício de categorização iniciou-se com a leitura flutuante do corpus. Na sequência, as categorias emergiram guiadas pelas perguntas norteadoras e pelo objetivo do estudo. Para isso, utilizou-se o tema como regra de recorte fundamentada nas unidades de registro, essas "unidades de significação que se libertam de um texto" (Bardin, 2011 p. 134). Participaram desse processo as autoras OMRA e CSR. $\mathrm{Na}$ apresentação dos resultados baseados nos relatos dos estudantes, adotou-se a letra "E", seguida do número associado a cada um dos discentes que cursaram a disciplina ESSC 1.

$\mathrm{Na}$ etapa inicial do ESSC 1, a professora, junto com os graduandos, optaram pela ambientação na própria UBS - 5- RSOC/B-DF para se apropriarem dos fluxos do serviço com vistas a responderem a possíveis perguntas dos usuários. A reflexão efetuada com eles, na semana subsequente, evidenciou a inocuidade dessa prática para o propósito desejado. Isso retrata o movimento de ação-reflexão-ação proporcionada pela pesquisaação, no decorrer da situação, por meio da avaliação dinâmica entre os pares quanto às ações, decisões e negociações no processo de mudança.

No contexto das práticas educacionais, vista numa perspectiva transformadora e emancipatória, as ideias dão lugar . . . a disposições para conhecer e agir de forma racional. Para além do "processo unilateral de emissão-transmissãorecepção, a comunicação resultante desse processo consolida tendências criadoras e construtivas (Thiollent, 2008, p. 80).

O resultado disso é que "a questão normativa . . . é controlada por meio da deliberação coletiva e submetida à aprovação dos grupos de educadores e dos alunos implicados” (Thiollent, 2008, p. 80).

A descrição da lógica processual desenvolvida nesse estudo contempla "os princípios fundantes da prática educativa” propostos por Franco (2005, p. 489) dentre os quais a ação conjunta entre pesquisador-pesquisados; a realização da pesquisa em ambientes onde acontecem as próprias práticas; a organização de condições de autoformação e emancipação aos sujeitos da ação; a criação de compromissos com a formação e o desenvolvimento de procedimentos crítico-reflexivos sobre a realidade; o desenvolvimento de uma dinâmica coletiva que permita o estabelecimento de referências contínuas e evolutivas com o coletivo, no sentido de apreensão dos significados construídos e em construção.

O Ministério de Estado da Saúde aprovou a Política Nacional de Atenção Básica (PNAB) (Portaria 2.488, 2011). No Distrito Federal, a Portaria 77 (2017) estabeleceu a Política de Atenção Primária à Saúde (APS). Para ser fiel à terminologia adotada em ambos os normativos, ao longo deste texto, foram utilizados os 2 termos, AB e APS sem uma padronização. 


\section{Resultados}

As principais categorias de análise desta pesquisa emergiram a partir da leitura e avaliação do diário de campo/Relatório escrito pelos graduandos durante o ESSC 1, e puderam ser sistematizados em 3 eixos de percepções: as habilidades desenvolvidas na formação profissional, os consensos alcançados para a constituição do CGUS e os desafios enfrentados para sua implementação. Cada um destes eixos serão abordados a seguir.

\subsection{Habilidades desenvolvidas na formação profissional}

Na chegada à UBS 5 - RSOC/B-DF, os graduandos perguntaram à gestora qual era sua demanda. Ela respondeu, de forma clara: a constituição do CGUS para inserir a comunidade nos processos decisórios em seu âmbito de atuação. Tal demanda corresponde a "lógicas mais centradas no usuário e no exercício do controle social", que implica em "promover a mobilização e a participação da comunidade buscando efetivar o controle social" (Portaria 2.488, 2011, p. 22. p. 45).

De acordo com Greenwood e Levin (2008, p. 101) a escuta da proposta da gestora corresponde à "integração da teoria com a praxis". Isso se materializou no

\section{[...] co-gerenciamento do processo de pesquisa por gestores e pesquisadores que trabalham juntos na definição do problema a ser enfrentado ... tendo em vista a mudança desejada; na interação do conhecimento local e profissional; bem como no empenho de enfatizar o papel dos agentes locais como sujeitos atuantes em uma situação holística (Greenwood \& Levin, 2008, p. 101).}

Os graduandos perceberam da seguinte forma o processo de aquisição das habilidades propostas: "ao longo do ESSC 1 foi possível construir e vivenciar as atribuições de Sanitarista frente à demanda da gestora (E1)" ou "O [ESSC 1] permitiu colocar em prática um pouco de cada atribuição que um Sanitarista é preparado para fazer (E5)". Essa habilidade de "mediar conflitos e conduzir processos comunicacionais e de trabalho que ... contribuam à humanização e à qualificação do atendimento dos sujeitos no âmbito do SUS" (Universidade de Brasília, 2009, p. 19) está proposta no PPC do curso de SC.

Para atender ao pleito da gestora, eles elaboraram um plano de trabalho em equipe, com prazos estabelecidos para o cumprimento das etapas dentro do período letivo e se dividiram em grupos para acelerar o processo. Um grupo destes graduandos fazia agendamento prévio para as visitas às instituições, efetuado em um telefone localizado no Hospital Regional de Ceilândia (HRC) situado há 4 quilômetros de distância da UBS 5 - RSOC/B$\mathrm{DF}$, enquanto outro grupo se dirigia para o CRSC que funciona no mesmo hospital.

A mobilização social se iniciou com as visitas dos graduandos para engajar as instituições com o objetivo de incluí-las no processo eletivo para o CGUS com vistas ao alcance de metas que trouxessem impacto para a comunidade. O principal caminho percorrido foi a atração das vontades, do sentimento e da decisão das pessoas que vivem na área de abrangência a UBS 5 - RSOC/B-DF. Outro aspecto indispensável à mobilização foi a corresponsabilidade pelo destino e pela realização das ações ao criar as condições para ampliar espaços de participação ativa com respeito à escuta qualificada dessas pessoas. Sabe-se que as pessoas são afetadas profundamente em suas crenças, atitudes e comportamentos pelas normas da comunidade onde vivem. Portanto, é o engajamento 
dos comunitários que torna possível a operacionalização de mudança nas normas da comunidade como primeiro nível de intervenção junto com essa comunidade (Spagnolo \& Fernandes, 2018). Consistente com essa premissa a PS se configura numa estratégia mediadora entre pessoas e ambiente que combina escolha pessoal com responsabilidade social para construir uma vida com mais saúde. (Nutbean, 1986).

Ao longo do percurso para realização do trabalho as reuniões com a gestora ocorriam na medida em que houvesse necessidade. Uma estudante avalia esses encontros da seguinte forma: "Percebia o respeito da gerência [da UBS 5 - RSOC/B-DF] às atribuições específicas do profissional Sanitarista (E5)”. A criação de um grupo na rede social WhatsApp (Ruano, Congote \& Torres, 2016) com os graduandos e a professora garantia a continuidade da conexão e da troca de informações. Ao passo que se mantinha periodicidade semanal de encontros com a professora para permitir o monitoramento do processo, a vigilância da adequação aos objetivos pedagógicos do período letivo e a tomada de novas iniciativas para catalisar o andamento das ações. Os demais atores foram se inserindo no processo à medida que se apresentava a necessidade.

Essa interlocução entre diferentes atores se faz necessária para cumprir o que estabelece a PNAB ao se referir ao processo de trabalho das equipes de AB: "implementar diretrizes de qualificação dos modelos de atenção e gestão, tais como a participação coletiva nos processos de gestão, a valorização, fomento à autonomia e protagonismo dos diferentes sujeitos implicados na produção de saúde, . . . a constituição de vínculos solidários, a identificação das necessidades sociais e organização do serviço em função delas, entre outras" (Ministério da Saúde, 2012, p. 40).

\subsection{Consensos Alcançados para a Constituição do Conselho Gestor da Unidade de Saúde}

A

[...] mobilização comunitária se baseia na premissa que, por natureza, os seres humanos são afetados profundamente em suas crenças, atitudes $e$ comportamentos pelas normas da comunidade onde vivem. Daí a importância de engajar os comunitários para operar mudança nas normas da comunidade como primeiro nível de intervenção (Guy, 1998, p. 5, tradução nossa).

A diversidade de objetivos existente no grupo de graduandos criou as condições para o consenso e a ação comunicativa cujo "objetivo fundamental consiste em assegurar o esclarecimento dos pontos de vista, desvendar a verdade, obter o consenso, através da ação cooperativa de todos" (Freitag, 2005, p. 39). Isso se reflete na percepção de E6: "Eu me identificava mais com o trabalho administrativo, mas como a demanda era mobilizar [constituir] o CGUS me inseri nas atividades a serem desenvolvidas para contribuir com a equipe. No fim do ESSC 1 considerei que foi uma boa experiência para desenvolver a habilidade da negociação e da persuasão”.

Ao mesmo tempo, a manifestação de E2 revela sua tendência inicial que foi adaptada para se adequar à resolução consensual do grupo: "Eu tinha preconceito com o CGUS e achava que o tempo do ESSC 1 seria insuficiente para a execução do processo eletivo, principalmente porque as etapas de construção desse processo dependiam da colaboração de outras pessoas. Mesmo considerando o prazo curto e os desafios a 
serem vencidos nos empenhamos no trabalho excedendo a carga horária do ESSC 1, trabalhando em casa fora dos horários estabelecidos para estarmos na UBS (UBS 5 -RSOC/B-DF) e conseguimos realizar a eleição no período letivo”.

“A experiência [de constituição do CGUS] potencializou nossas capacidades de escuta qualificada, estratégias de abordagem/poder de persuasão, além da capacidade de diálogo e negociação, [da] capacidade de lidar com prazos e demandas, tivemos dimensão dos trâmites legais para implementação do CGUS e de toda necessidade burocrática dos serviços públicos, o que nos deu base e experiências no que se refere a relações interpessoais" (E5). A intersubjetividade gerada entre os participantes contempla "a interação mediatizada pela linguagem" como resultado da "interação comunicativa que visa à autonomia da espécie” (Freitag, 2005, p. 109). Esse tipo de ação cooperativa e coordenada permeou o processo formativo em saúde ao tempo em que desvelou a associação do "pensamento crítico à resolução de problemas relacionados com situações práticas e à tomada de decisão consciente e informada” (Pinto, 2011, p.21) resultante das múltiplas oportunidades de aprendizagem.

"Uma habilidade desenvolvida foi encontrar novas formas de abordagem às instituições da área de abrangência da UBS 5 - RSOC/B-DF para exercerem a cidadania percebendo a importância de sua participação e sua capacidade para pleitear uma vaga no CGUS” (E4).

As etapas da constituição do CGUS estão sumarizadas a seguir: atualização dos endereços e contatos telefônicos das instituições mapeadas no território de abrangência da UBS 5 RSOC/B-DF, com potencial para se habilitarem à eleição do CGUS, segundo o arcabouço normativo em vigor no Brasil (Lei n. 8.080, 1990; Lei n. 8.142, 1990) e no DF (Lei 4.604, 2011; Resolução n. 002, 1995; Portaria n. 77, 2017); constituição da Comissão Eleitoral (CE), para garantir lisura ao processo eletivo preservando-o de eventuais impugnações, além da busca ativa das instituições adscritas ao território da UBS 5 - RSOC/B-DF.

O objetivo das visitas às instituições era divulgar as pré-condições que as habilitavam a concorrerem ao processo eletivo e negociar junto com elas uma data para realizar a eleição do CGUS. Nesses contatos, os graduandos valorizaram a comunicação e o relacionamento como dimensão importante nas visitas às diferentes instituições; fizeram a escuta qualificada, resguardando o respeito às identidades locais; validaram a conversa que selou a parceria com o envio de uma carta chancelada pela DIRAPS para formalizar o convite e confirmar os documentos necessários.

"Percebemos a contradição entre a existência de espaços de participação [em Conselhos de Saúde] que estão abertos e a ausência das instituições nesses espaços. Por essa razão houve necessidade de, não apenas divulgar o processo de eleição, mas conquistar a vontade das pessoas para participarem do processo eletivo" (E3). A solicitação da gestora desencadeou a possibilidade de decidir sobre saúde mediante o estabelecimento de fluxos comunicacionais começando pela periferia.

Nesse sentido, logo no início do processo os graduandos participaram como ouvintes do CRSC para buscar informações sobre o normativo legal para eleição do CGUS; em seguida recorreram ao CDS-DF para coletar a legislação específica do DF referente ao tema; e, na sequência, se apropriaram do normativo legal concernente à participação da comunidade no CGUS em âmbito nacional e do DF. Os graduandos mantiveram 
a "comunicação constante com o CRSC e o CDS-DF, visto que a experiência [de constituição do CGUS] ainda não havia sido implantada (na RSOC/B-DF) e não se sabia os passos necessários para fazê-lo, então a todo momento surgiam dúvidas a serem sanadas" (E5).

No dia marcado a CE deflagrou formalmente o processo eletivo ao CGUS conforme dispositivo legal vigente para assegurar a efetividade do aparato normativo relacionado à participação da comunidade na tomada de decisão. Na etapa subsequente os graduandos apresentaram os resultados do trabalho desenvolvido ao longo do semestre aos servidores da UBS 5 - RSOC/B-DF. Em seguida elaboraram a versão preliminar de um Manual instrucional composto pela legislação correlata e pelas etapas de constituição do CGUS para subsidiar sua implementação em outras UBS. "O mais gratificante foi conseguir entregar o produto do nosso estágio no tempo estipulado e ver que pessoas se mobilizaram pela causa" (E6).

Para além da sequência de tecnicalidades envolvidas no processo, veio em relevo uma multiplicidade de aspectos que parece importante serem destacados: os diálogos sem interrupção entre os graduandos para superação de eventuais ruídos de comunicação entre eles mediatizados pelo WhatsApp; a dedicação de tempo de trabalho superior ao que prevê a disciplina ESSC 1; bem como a interlocução constante com o CRSC e com o CDS-DF ao longo do semestre. Isso facilitou o esclarecimento dos trâmites legais e burocráticos com vistas ao atendimento da necessidade expressa pela gestora da UBS 5 - RSOC/B-DF. Ao tempo em que estabeleceram as parcerias com outras instituições, os graduandos atuaram com base no tipo de comunicação preconizada por Habermas (2012). E, em seu empenho para deflagrar o processo eletivo do CGUS, tornaram-se também sujeito e produto de sua ação.

Essa rede de relacionamento UnB/SUS proporcionou a concretização de alguns tópicos do PPC de Saúde Coletiva da FCE-UnB: os graduandos se apropriaram
[...] de uma educação comprometida com possibilidades dos sujeitos operarem escolhas, participarem da condução de sua vida, de sua coletividade e do seu próprio processo de formação; favoreceram oportunidades de desvelamento das diferentes realidades das quais participaram, seja da sua reprodução como de sua transformação; contribuíram com a construção da PS e da mobilização de sujeitos e coletividades; compartilharam o saber técnico científico com o saber popular e a construção de novas estratégias e alternativas (Universidade de Brasília, 2009, p. 16).

A participação vivenciada pelos componentes dessa experiência está intimamente relacionada ao conceito de cidadania ativa, de reivindicação política, de socialização de saberes, de decisões e da colaboração no planejamento da UBS. As instituições assumiram o papel de sujeito de direito e, a população por elas representada passou a tomar parte no planejamento de metas, na execução e avaliação das ações desenvolvidas. Nessa perspectiva colocaram em relevo o papel da saúde em seu aspecto positivo de atendimento às necessidades do sujeito e de desenvolvimento de suas potencialidades para enfrentar os desafios do cotidiano no ambiente onde vivem, moram e trabalham. Assim fazendo atenderam à recomendação para "implementar a participação coletiva nos processos de gestão, na identificação de necessidades e na organização dos serviços" 
proposta nos processos de trabalho das equipes de AB. Tudo isso está em consonância com o ponto de atenção aonde se desenrolou o processo, a APS, que é "porta de entrada e centro de comunicação com a Rede de Atenção à Saúde” (Ministério da Saúde, 2012).

\subsection{Desafios para a Implementação do Conselho Gestor da Unidade de Saúde}

Devido à duração do período letivo e aos trâmites que antecedem o processo eleitoral para CGUS, os graduandos precisaram de muita determinação para concluir a tempo como percebe E6 "para a implementação do CGUS foi necessário que tivéssemos iniciativa, espírito de liderança, dedicação e muita responsabilidade para cumprirmos o que nos foi proposto, que para nós parecia impossível de realizar em tão pouco tempo".

O problema mais frequente relatado por todos os graduandos se referiu à "dificuldade de locomoção para nos dirigirmos até as instituições" (E4) ou como enfatiza E6: "a falta de recursos físicos como (a inexistência) de telefone (na UBS 5 - RSOC/B-DF), o que obrigava nos deslocarmos até o HRC para usar o telefone”. Esse aspecto é evidenciado também na fala de E3: "não havia carros disponíveis, o transporte para irmos às instituições ficou por nossa conta. Em alguns momentos para os contatos por telefone tivemos que usar os nossos telefones".

Ao estabelecerem a rede de relacionamento com a gestora da UBS 5- RSOC/B-DF, o CRSC, o CDS-DF, a DIRAPS e as instituições, os graduandos desencadearam a interconexão e o entendimento entre os participantes para alcançarem a mudança pretendida. "Foi uma experiência desafiadora, pois havia informações desencontradas e trâmites legais/burocráticos para a execução da tarefa [de implementação do CGUS]"(E5). A aprendizagem se traduziu em "saber pesquisar, saber organizar o próprio trabalho ...." (Gadotti, 2000, p. 8).

Outra consequência dessa experiência foi a oportunidade de os graduandos exercitarem suas atribuições como Sanitaristas, bem como o fortalecimento da identificação deles com sua futura profissão como evidencia a fala de um estudante: "O ESSC 1 foi uma oportunidade de fazermos o nexo da teoria com a prática nos proporcionando o privilégio de crescermos profissionalmente" (E1). O cumprimento do ESSC 1 na APS propiciou a geração do conhecimento a partir do serviço. Mais um resultado particularmente apreciado foi o entendimento do território para além da dimensão espacial de residência da população em comunidades delimitadas, para uma percepção de pertencimento; e o empenho dos componentes envolvidos no esforço de lutar pelo direito à saúde e a mobilização das pessoas por essa causa. Após o retorno do cenário de práticas os graduandos sentiram-se realizados por terem enfrentado desafios, encontrado soluções criativas, por terem colocado em prática suas atribuições como Sanitaristas e pela satisfação gerada no processo coletivo.

Devido ao pioneirismo da ação na RSOC/B-DF, as principais barreiras enfrentadas no processo foram as informações desencontradas ou a ausência delas acerca da implementação do Conselho Gestor; a atualização de endereço das instituições que tomou um tempo precioso; a dificuldade de conseguir telefones para fazer os contatos iniciais, para isso foi preciso deslocar-se para um local a $4 \mathrm{~km}$ de distância da UBS 5 RSOC/B-DF; as experiências anteriores vivenciadas por alguns possíveis candidatos que 
os levavam a desconfiar de processos participativos por causa de manobras usadas por outros gestores para legitimar seus interesses; a dificuldade de superar a divergência entre o discurso e a prática percebida na expectativa de barganha manifestada por algumas pessoas nas instituições visitadas; a postura tendenciosa a centrar o interesse em defesa do próprio segmento; e a indisponibilidade de tempo gasto nessas instâncias de participação incompatível com a luta pela subsistência das pessoas em geral.

Os facilitadores mais relevantes no decorrer dessa experiência foram a determinação de cada um dos participantes para superar as barreiras encontradas ao longo do processo; a capacidade dos graduandos se reinventarem para contornar alguns obstáculos, aparentemente intransponíveis, que se apresentaram; o comprometimento e a vontade de fazer acontecer da gestora, dos graduandos e das instituições que se dispuseram a participar do processo; o esforço de adaptação da linguagem e dos argumentos na comunicação com as pessoas nas instituições; o incremento da troca de saberes mediante a convivência com as diferenças nesse coletivo plural; além do desenvolvimento de habilidades sociais e políticas nos graduandos, nos participantes e nas instituições que representam. E, finalmente, a descoberta da alegria e da beleza "de ser um eterno aprendiz".

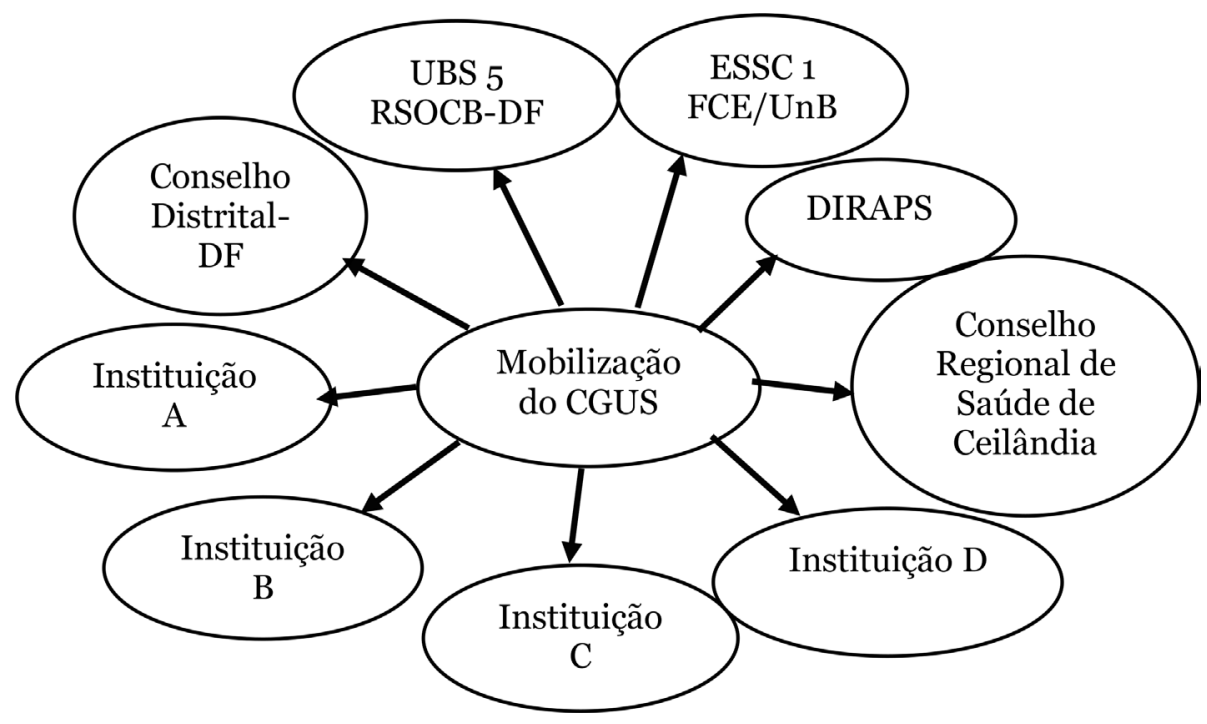

Figura 1 - Diagrama da rede de relacionamento e parcerias para constituição do Conselho Gestor na Unidade Básica de Saúde 5 da Região Oeste Ceilândia/Brazlândia - DF

\section{Conclusões}

A conjunção da teoria vinculada às trilhas de aprendizagem estabelecidas no Projeto Político do Curso de Saúde Coletiva, à formação para a autonomia e ao emprego de metodologias participativas por meio da pesquisa-ação constituíram elementos formadores da emancipação dos sujeitos (graduandos e participantes dos grupos).

Nessa perspectiva demostra-se que a Teoria do Agir Comunicativo constitui poderoso instrumento analítico no estudo da estruturação de CGUS com participação popular, 
que são uma demanda importante para o aprofundamento democrático das sociedades contemporâneas.

Os graduandos mostraram competência ao desenvolverem estratégias de diálogo, negociação nos relacionamentos interpessoais e interinstitucionais; na capacidade de cumprir prazos exíguos para atender demandas burocráticas com vistas à realização da eleição do CGUS; e no exercício do protagonismo nos processos decisórios com vistas a atingir metas específicas com impacto para a sociedade.

Tal aproximação com o mundo real e o emprego da pesquisa-ação desencadearam a convergência conceitual com as tecnologias educacionais e sociais adotadas nesse estudo. Sua utilização propiciou articulação da demanda da gestora e as demandas sociais de maneira eficaz.

A experiência na APS, a articulação com a gestora da UBS 5 - RSOC/B-DF, com o CRSC, com o CDS-DF e com a DIRAPS inseriram os graduandos numa dinâmica pedagógica que permitiu articular o saber, o conhecimento, a comunidade e o ambiente.

A construção da rede de relacionamento institucional que envolveu estado e sociedade resultou na eleição do CGUS do UBS 5 RSCB-DF; na atuação efetiva dos graduandos na APS e no estreitamento do vínculo entre eles e a comunidade; na inserção da comunidade no processo de mudança por meio de uma ação concreta e em sua integração ao cenário que incorpora atores sociais locais ao processo político. Além disso, a diversidade de iniciativas desenvolvidas propiciou a integração da teoria com a prática e proporcionou a construção de significados para eles.

Ao construírem conjuntamente com diferentes segmentos sociais o processo eletivo do CGUS, os graduandos vivenciaram a participação deles mesmos e dos grupos com os quais trabalharam, perceberam sua importância na real concretização na APS, experimentaram os efeitos da autonomia, da emancipação e do 'empoderamento'.

\section{Referências}

Bardin, L. (2011). Análise de conteúdo. ( $3^{\mathrm{a}}$ reimp). Lisboa: Ediçoes 70.

Bava, S. C. (2004). Tecnologia social e desenvolvimento local. In: Tecnologia social: uma estratégia para o desenvolvimento (pp. 103-116). Rio de Janeiro: Fundação Banco do Brasil.

Berbel, N. A. N. (2011). Metodologias ativas e a promoção da autonomia de estudantes. Semina: Ciências Sociais e Humanas, 32(1), 25-40.

Bezerra, A. P.S., et al. (2013). Quem são os novos sanitaristas e qual seu papel?. Tempus: Actas de Saúde Coletiva, 7(3), 57-62.

Gouveia L. M. B. (2004). Sociedade da Informação: Notas de contribuição para uma definição operacional. Porto: Universidade Fernando Pessoa.

Braga, C. S., Henriques, M. S., \& Mafra, R. L. M. (2004). O planejamento da comunicação para a mobilização social: em busca da co-responsabilidade. In: Henriques, M. S. (Org.), Comunicação e estratégias de mobilização social. Belo Horizonte: Autêntica. 
Brasil. Ministério da Saúde. Secretaria de Políticas de Saúde (2002). Projeto Promoção da Saúde. As Cartas da Promoção da Saúde / Ministério da Saúde, Secretaria de Políticas de Saúde, Projeto Promoção da Saúde. Brasília: Ministério da Saúde.

Constituição da República Federativa do Brasil de 1988. Recuperado de http://www.stf.jus.br/arquivo/cms/legislacaoConstituicao/anexo/CF.pdf.

Dionne, H. (2007). A pesquisa-ação para o desenvolvimento local. Brasília: Liber Livro.

Franco, M. A. S. (2005). Pedagogia da pesquisa-ação. Educação e Pesquisa, 31(3), 483-502.

Freitag, B. (2005). Dialogando com Jürgen Habermas. Rio de Janeiro: Tempo Brasileiro.

Gadotti, M. (2000). Perspectivas atuais da Educação. São Paulo em Perspectiva, 14(2), 3-11. Recuperado de http://www.scielo.br/pdf/spp/v14n2/9782.pdf.

Greenwood, D. J., \& Levin, M. (2008). The reformed social sciences to reform the university: mission impossible? Learning and Teaching, 1(1), 89-121. Retrieved from https://www.researchgate.net/publication/311344453_Reform_of_the_ social_sciences_and_of_universities_through_action_research.

Guy, L. (1998). An introduction to community development: activation to evaluation. Retrieved from http://www.wcsap.org/introduction-community-developmentactivation-evaluation.

Habermas, J. (2003). Direito e democracia entre factilidade e validade. Rio de Janeiro: Tempo Brasileiro.

Habermas, J. (2012). Teoria do Agir Comunicativo: racionalidade da ação e racionalização social. São Paulo: WMF Martins Fontes.

Otero, MR. (2004). Reflexões sobre a construção de um conceito de Tecnologia Social. In: Tecnologia Social no Brasil: direito à ciência e ciência para cidadania: Caderno de Debate. São Paulo: ITS.

Keemis, S., \& McTaggart, R. (2005). Participatory Action Research. In: Dezin, N. K., \& Lincoln, Y. S. (Eds.). The handbook of qualitative research (3rd ed., pp. 272-330). Thousand Oaks, CA: Sage.

Lei n. 8.o8o, de 19 de setembro de 1990. Dispõe sobre as condições para a promoção, proteção e recuperação da saúde, a organização e o funcionamento dos serviços correspondentes e dá outras providências. Recuperado de http://www.planalto.gov.br/ccivil_o3/leis/18080.htm.

Lei n. 8.142, de 28 de dezembro de 1990. Dispõe sobre a participação da comunidade na gestãodoSistema ÚnicodeSaúde(SUS) esobreastransferênciasintergovernamentais de recursos financeiros na área da saúde e dá outras providências. Recuperado de http://www.planalto.gov.br/ccivil_o3/leis/18142.htm.

Lei $n^{o}$ 4.604, de 15 de julho de 2011. Dispõe sobre a organização, a composição e as atribuições do Conselho de Saúde do Distrito Federal. Recuperado de http://www.tc.df.gov.br/SINJ/Norma/68849/Lei_4604_15_07_2011.html. 
Luppicini, R. (2005). A system definition of educational technology in society. Educational Technology \& Society, 8(3), 103-109.

Menezes, A. A. (2014). Educação \& emancipação: por uma racionalidade éticocomunicativa. Maceió: EDUFAL.

Moresi, E. A. D. (2017). Tecnologia Social: a doação na perspectiva do aplicativo Solidarius. RISTI - Revista Ibérica de Sistemas e Tecnologias de Informação, (spe23), 1-16. Recuperado de http://www.scielo.mec.pt/pdf/rist/n23/n23ao2.pdf.

Nutbeam, D. (1986). Glosario de promoción de la salud. Health Promotion. 1(1),113-127.

Pinto, I. R. F. (2011). Atividades promotoras de pensamento crítico: sua eficácia em alunos de ciências da natureza do $5^{\circ}$ ano de escolaridade. Dissertação de Mestrado, Escola Superior de Educação de Lisboa, Lisboa, Portugal. Recuperado de https://repositorio.ipl.pt/bitstream/10400.21/1789/1/Atividades\%20 promotoras\%2ode\%2opensamento\%20cr\%C3\%ADtico.pdf.

Portaria n. 2.446, de 11 de novembro de 2014. Redefine a Política Nacional de Promoção da Saúde (PNPS). Recuperado de http://bvsms.saude.gov.br/bvs/saudelegis/ gm/2014/prt2446_11_11_2014.html.

Portaria n. 2.488, de 21 de outubro de 2011. Aprova a Política Nacional de Atenção Básica, estabelecendo a revisão de diretrizes para a organização da Atenção Básica, no âmbito do Sistema Único de Saúde (SUS). Recuperado de http://189.28.128.100/ dab/docs/publicacoes/geral/pnab.pdf.

Portaria n. 77, de 14 de fevereiro de 2017. Estabelece a Política de Atenção Primária à Saúde do Distrito Federal. Recuperado de https://www.tc.df.gov.br/SINJ/ DetalhesDeNorma.aspx?id_norma=b41d856d8d554d4b95431cdd9eeo0521.

Resolução CSDF 002, de o7 de março de 1995. Diretrizes para constituição/instalação dos conselhos gestores das unidades de saíde. Recuperado de http://www.saude. df.gov.br/wp-conteudo/uploads/2018/04/Resolucao_o02-95_constituicao_dos_ conselhos_gestores.pdf.

Resolução CSDF no 39o, de 22 de maio de 2012. Cria os Conselhos Regionais de Saúde do Distrito Federal. Recuperado de http://www.tc.df.gov.br/SINJ/Norma/71745/ Resolu_o_390_22_05_2012.html.

Rocha, J. et al. (2018). Mobilização do Conselho Gestor com o Uso de Tecnologias Sociais In Congresso Ibero-Americano em Investigação Qualitativa. In: Atas - Investigação Qualitativa em Saúde CIAIQ 2018 (pp. 595-604). Fortaleza: A utor. Recuperado de https://proceedings.ciaiq.org/index.php/ciaiq2018/article/view/1825/1777.

Ruano, L. E., Congote, E. L., \& Torres, A. E. (2016). Comunicación e interacción por el uso de dispositivos tecnológicos y redes sociales virtuales en estudiantes universitarios. RISTI - Revista Ibérica de Sistemas e Tecnologias de Informação, (19), 15-31. Recuperado de http://www.scielo.mec.pt/pdf/rist/n19/n19a03.pdf. 
Spagnolo, R. S., \& Fernandes, V. C. (2018). Construção de práticas emancipatórias com Conselhos Municipais de Saúde. In: Congresso Ibero-Americano em Investigação Qualitativa, Atas - Investigação Qualitativa em Saúde CIAIQ 2018 (pp. 2833). Foraleza: Autor. Recuperado de https://proceedings.ciaiq.org/index.php/ ciaiq2018/article/view/1761/1714.

Thiollent, M. (2008). Metodologia da pesquisa-ação (16 ed.). São Paulo: Cortez.

Universidade de Brasília (2009). Projeto Político-Pedagógico. Brasília: UnB. Recuperado de http://fce.unb.br/images/documentos/graduacao/saudecoletiva/ ppp/ppp_sc_19-08.pdf. 